\title{
Value of cyst localization to predict cystobiliary communication in patients undergoing conservative surgery with hydatid cyst
}

This article was published in the following Dove Press journal:

Therapeutics and Clinical Risk Management

I5 June 2016

Number of times this article has been viewed

\author{
Bircan Alan' \\ Murat Kapan² \\ Memik Teke' \\ Salih Hattapoğlu' \\ Zülfü Arıkanoğlu² \\ 'Department of Radiology, \\ ${ }^{2}$ Department of General Surgery, \\ Faculty of Medicine, Dicle University, \\ Diyarbakır, Turkey
}

Objective: The objectives of this study were to investigate the relationship between the segmental localization of liver hydatid cyst by computed tomography (CT) and the presence of cystobiliary communication (CBC) and to identify the risk factors for CBC.

Patients and methods: One hundred and eleven of 163 patients who underwent liver hydatid surgery between January 2011 and September 2014 were included in this study and analyzed retrospectively. The size, number, stage, and segmental and lobar localization of the cysts were investigated by $\mathrm{CT}$. The presence of $\mathrm{CBC}$ and preoperative laboratory findings were recorded from operation notes.

Results: $\mathrm{CBC}$ was more frequent in single large cysts. $\mathrm{CBC}$ was most commonly detected in segment $1(50 \%), 8(48.3 \%), 7(41.2 \%)$, and $4(40 \%)$. CBC was more frequent in the right lobe $(40.4 \%)$ and Gharbi stage $3(41.8 \%)$ and $4(55.6 \%)$ lesions. There were no differences in CBC according to distance from the hilus. In addition, preoperative total bilirubin, direct bilirubin, alkaline phosphatase (ALP), and gamma-glutamyl transferase (GGT) elevations were associated with higher $\mathrm{CBC}$ frequency $(P<0.05)$. Cyst diameter, number of cysts, and ALP and GGT elevations were independent predictors of $\mathrm{CBC}$ presence.

Conclusion: The evaluation of hydatid cyst diameter, morphological stage, and segmental and lobar localization by abdominal CT and measurement of preoperative cyst diameter, number of cysts, and ALP and GGT values may predict the presence of CBC.

Keywords: hydatid cyst, computed tomography, hydatid cyst localization, cystobiliary communication

\section{Introduction}

Hydatid cyst is a parasitic zoonotic illness caused by Echinococcus granulosus. It is endemic in many parts of the world, and is the most common cause of hepatic cysts in the endemic areas. Although hydatid cysts can develop in any location in the human body, the most commonly affected organ is the liver $(60 \%-70 \%)$, followed by lungs $(20 \%-30 \%)^{1,2}$

A connection between the liver and biliary tract is one of the most common and serious complications of hydatid cysts, constituting $60 \%$ of complicated cases. ${ }^{3-6}$ Cystobiliary communication (CBC) can be determined pre-, intra-, and postoperatively. ${ }^{7}$ If the diagnosis of $\mathrm{CBC}$ is made pre- or intraoperatively, postoperative morbidity and biliary fistula development occur at a lower rate. ${ }^{3-6}$ The $\mathrm{CBC}$ may be minor or major. ${ }^{4,8}$ In major $\mathrm{CBC}$, cyst contents, such as hydatid debris, daughter cysts, and major fragments of the germinative membrane, are found in the common bile duct and can manifest with serious clinical conditions such as obstructive jaundice and cholangitis.
Correspondence: Bircan Alan Department of Radiology, Faculty of Medicine, Dicle University, Seyrantepe mevkii, 21280 Diyarbakır, Turkey Tel $+90412248800 I / 4738$ Email bircanalan@hotmail.com 
Hence, the diagnosis is easy. However, in minor CBC, cyst fluid, scolices, small daughter cysts, and minor fragments of the endocyst membranes pass into the biliary tree and usually remain asymptomatic. ${ }^{8,9}$ The diagnosis may be recognized at the surgery, but if it remains undetected, postoperative biliary leakage may result in complication. ${ }^{10}$

The useful imaging modalities for the diagnosis of the CBC are ultrasound, computed tomography (CT), magnetic resonance cholangiopancreatography, and endoscopic retrograde cholangiopancreatography. ${ }^{2,10,11}$

The aims of this study were to investigate the association between the segmental localization of the cyst in preoperative abdominal CT and the occurrence of $\mathrm{CBC}$, and to identify the risk factors for $\mathrm{CBC}$.

\section{Patients and methods}

This retrospective study was approved by the Dicle University Medical Faculty Ethıcs Committee For Noninterventional studies [177]. Given the retrospective nature of the study, patient consent was not obtained. One hundred sixty-three patients undergoing hydatid cyst surgery between January 2011 and October 2014 in the Department of General Surgery, Faculty of Medicine, Dicle University were retrospectively analyzed. We included 111 patients (32 males and 79 females) with liver hydatid cyst in this study. In all patients, the diagnosis was confirmed by abdominal CT and ultrasound. Ten patients treated with pericystectomy or hepatectomy and 42 patients without preoperative abdominal CT or whose images were inaccessible were excluded from this study. Patients undergoing conservative surgery who had preoperative abdominal CT were included in this study. A total of 152 cysts were found in the patients.

\section{CT protocol}

All the scans were performed using Philips Brilliance 64-slice multidetector CT (Philips Medical Systems, Cleveland, OH, USA). Nonionic iodine solution was used as the contrast medium. A volume of $100 \mathrm{~mL}$ of nonionic contrast medium was injected through the antecubital vein at a speed of $2-4 \mathrm{~mL} / \mathrm{s}$ with an automatic power injector. The whole abdomen, the region between the diaphragm and the symphysis pubis, was scanned in 8-10 seconds. Dose parameters were $250 \mathrm{mAs}$ and $120 \mathrm{kV}$. The scan parameters were as follows: slice thickness $3 \mathrm{~mm}$, pitch factor $0.99-1.11$, rotation time $0.75-1$ seconds, and collimation $0.625 \mathrm{~mm}$.

Abdominal ultrasound was carried out by an experienced radiologist (with 5 years of experience in abdominal ultrasound imaging) using the Toshiba Aplio XG (Tokyo, Japan) apparatus and a $3 \mathrm{MHz}$ convex probe with the patient in the supine and lateral decubitus position.

Demographic findings and preoperative laboratory workups, including white blood cell count, alanine transaminase, aspartate transaminase, alkaline phosphatase (ALP), gammaglutamyl transferase (GGT), total bilirubin (TB), direct bilirubin (DB), were recorded. The number, size, stage, and lobar and segmental localization of the hydatid cysts were determined by abdominal CT. Operation findings and patient files were examined retrospectively to confirm $\mathrm{CBC}$ presence and correlation with CT findings. The Couinaud classification of liver anatomy was used for the localization of the cysts. ${ }^{12,13}$ Additionally, cysts were classified based on the liver lobe location (right, left, and caudate lobes). The patients were further categorized into two groups according to the location of cysts, close to the hilus (segments 1, 3, 4b, 5, and 6) or away from the hilus (segments 2, 4a, 7, and 8). ${ }^{8}$ The stage of each cyst was determined according to Gharbi classification. ${ }^{14}$

The patient groups were divided into two subgroups, patients with $\mathrm{CBC}$ and without $\mathrm{CBC}$, and the parameters were compared between the subgroups. The assessment of demographic findings (age, sex), laboratory parameters, and cyst number was conducted at the patient level. However, each cyst was considered separately in the assessment of location, size, stage, and closeness of the cyst to the hilus (Figures 1 and 2).

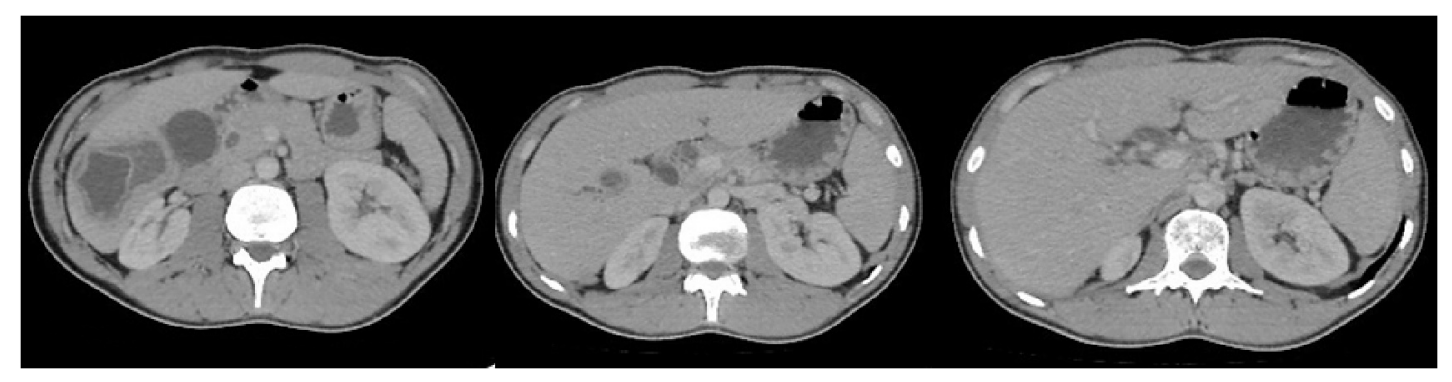

Figure I A 17-year-old male with pain in the right upper abdomen.

Notes: Axial computed tomography revealed two cysts. One of them was of type 2, localized in segment 7 , and $6 \mathrm{~cm}$ in diameter. The other was of type I, localized in segment 5 , and $3.5 \mathrm{~cm}$ in diameter. Dilatation and hyperdense attenuation materials (daughter vesicles) were observed in common and left hepatic bile duct. 


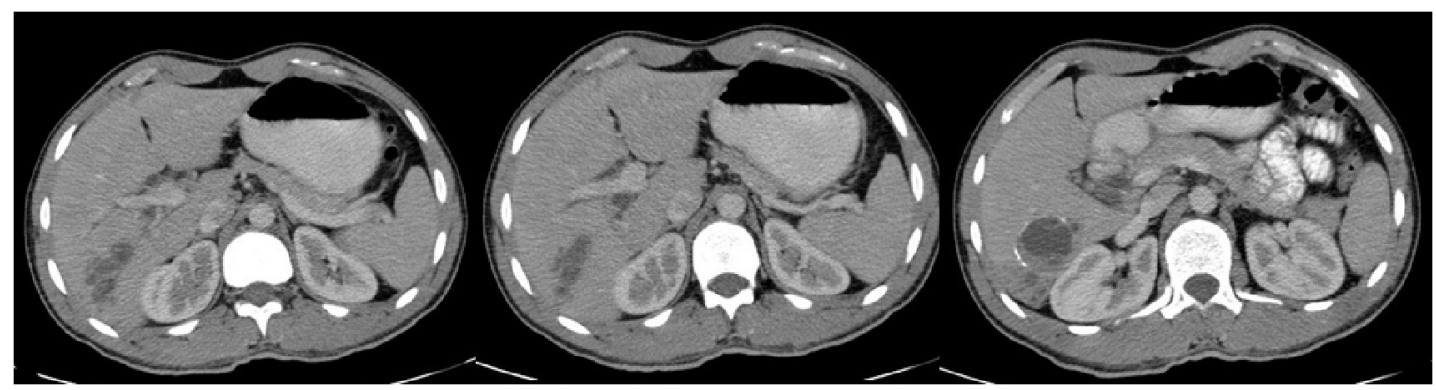

Figure 2 A 20-year-old male with pain in the right upper abdomen.

Notes: Axial CT revealed a cyst. The cyst was of type 4, localized in segment 6 , and $4 \mathrm{~cm}$ in diameter. CT showed mild-moderate dilatation in the right hepatic bile duct and intrahepatic defect in the subcapsular area of the posterior cyst wall.

Abbreviation: CT, computed tomography.

On ultrasound, $\mathrm{CBC}$ was defined by the detection of different anechoic and hypoechoic images without acoustic shadowing in the biliary tract. On abdominal CT, CBC was defined by the detection of high-density materials in the intrahepatic bile ducts, lack of cyst wall integrity, and dilatation of biliary tree in the porta hepatis.

\section{Statistical analysis}

Data analysis was performed using SPSS 13.0 (SPSS Inc., Chicago, IL, USA). Quantitative values were represented as mean \pm standard deviation, while independent categories were represented as number (\%). The test of normality was analyzed by the Kolmogorov-Smirnov test. In group comparisons, Mann-Whitney $U$-test was used for nonparametric data and Student's $t$-test was used for parametric data. Independent categories were evaluated by chi-square tests. The statistically different continuous variables present in the $\mathrm{CBC}$ group were evaluated to determine the predicted factor on $\mathrm{CBC}$ by using the linear regression test. A $P$-value of $<0.05$ was considered to be statistically significant.

\section{Results}

A total of 111 patients, $32(28.8 \%)$ males and 79 (71.2\%) females, were included in this study. The mean age of the patients was $39.3 \pm 16.5$ years. A total of 152 cysts were detected. The mean number of the cysts was $1.33 \pm 0.73$. The mean diameter of the cysts was $73.17 \pm 34.16 \mathrm{~mm}$ (20-200 mm).

The localization of cysts according to Couinaud segments is shown in Table 1. Hydatid cysts were more frequent in segments 4,8 , and 6 . A total of $55 \mathrm{CBCs}$ were detected in 152 cysts. While 25 (45\%) of the CBCs were detected by abdominal CT, 30 (55\%) of them were detected from operation notes. On abdominal CT, the CBCs were most frequently located in segment 1 (50\%), 8 (48.3\%), 7 (41.2\%), and $4(40 \%)$.
Table 2 shows the distribution of cysts in terms of lobar location. Most of the cysts were located in the right lobe (61.8\%), showed significantly higher rate (40.4\%) of CBC $(P<0.05)$.

The distance of cysts from the hilus is summarized in Table 3. Although $55.3 \%$ of the cysts were located close to the hilus, there was no difference in terms of $\mathrm{CBC}$ development between cysts close to and away from the hilus.

The distribution of the cysts according to Gharbi classification is given in Table 4. Of the surgically excised cysts, $40.8 \%$ were stage 1 and $36.2 \%$ were stage 3 . CBC was most frequent in stage $4(55.6 \%)$ and $3(41.8 \%)$ cysts.

The relationship between demographic characteristics, preoperative laboratory findings, and $\mathrm{CBC}$ is shown in Table 5. Significantly higher rates of $\mathrm{CBC}$ were observed in single large cysts compared to multiple small cysts. Additionally, patients with higher preoperative TB, DB, ALP, and GGT levels showed increased CBC development $(P<0.05)$.

ALP, GGT, cyst diameter, and number of cysts were the independent predictors of CBC presence (Table 6).

Table I The distribution of the cysts in the liver according to the Couinaud segmental anatomy and the relationship with CBC

\begin{tabular}{lll}
\hline Segment & CBC (\%) & Total (\%) \\
\hline 1 & $1 / 2(50)$ & $2(1.3)$ \\
2 & $3 / 22(13.6)$ & $22(14.5)$ \\
3 & $1 / 4(25)$ & $4(2.6)$ \\
4 & $12 / 30(40)$ & $30(19.7)$ \\
5 & $8 / 21(38.1)$ & $21(13.8)$ \\
6 & $9 / 27(33.3)$ & $27(17.8)$ \\
7 & $7 / 17(41.2)$ & $17(11.2)$ \\
8 & $14 / 29(48.3)$ & $29(19.1)$ \\
Total & $55 / 152(36.2)$ & $155(100)$ \\
\hline
\end{tabular}

Notes: ${ }^{\mathrm{T}}$ The rate of $\mathrm{CBC}$ in each stage. ${ }^{\mathrm{b}} \mathrm{The}$ rate of cyst localization. Abbreviation: $\mathrm{CBC}$, cystobiliary communication. 
Table 2 The distribution of the cysts in the liver according to lobe anatomy and the relationship with $\mathrm{CBC}$

\begin{tabular}{lll}
\hline Lobe & CBC (\%) & Total (\%) \\
\hline Caudate & I/2 (50) & $2(1.3)$ \\
Left & $16 / 56(28.6)$ & $56(36.8)$ \\
Right & $38 / 94(40.4)$ & $94(61.8)$ \\
Total & $55 / 152(36.2)$ & $152(100)$ \\
\hline
\end{tabular}

Notes: ${ }^{\mathrm{T} T h e}$ rate of $\mathrm{CBC}$ in each stage. ${ }^{\mathrm{b}} \mathrm{The}$ rate of cyst localization.

Abbreviation: $\mathrm{CBC}$, cystobiliary communication.

\section{Discussion}

$\mathrm{CBC}$ is quite common in the liver hydatid cyst. ${ }^{15} \mathrm{CBC}$ is the most important reason of morbidity and mortality associated with hepatic hydatid cysts. ${ }^{16}$ Two theories have been proposed about the pathogenesis of CBC. First, the hydatid cyst progressively compresses the biliary tract wall, which causes necrosis and eventually CBC. Second, small biliary radicals in the pericystic wall generate high intracystic pressure, resulting in atrophy followed by the rupture of the biliary radicals. ${ }^{3-5,9}$ Although the connection between cysts and bile ducts is present in $80 \%-90 \%$ of the patients, clinically apparent $\mathrm{CBC}$ occurs in $2 \%-42 \%$ of the patients in different series. ${ }^{3,7-9,17-21} \mathrm{CBC}$ presence was reported as $28.4 \%, 27 \%$, in the studies of Demircan et $\mathrm{a}^{22}$ and Kayaalp et al, ${ }^{8}$ respectively. In accordance with the literature, CBC was present in $36.2 \%$ of our patients. Careful evaluation of clinical, laboratory, and radiological signs can help identify CBC preoperatively. ${ }^{23}$ Understanding the parameters related to the frequency of $\mathrm{CBC}$ may reveal the requirements for more careful assessment, such as optimal exploration of the liver, increasing the intrahepatic bile duct pressure by squeezing the gallbladder, giving methylene blue or total parenteral solutions via the cystic duct. Preoperative diagnosis of $\mathrm{CBC}$ and implementation of the necessary procedures may result in significantly reduced morbidity. ${ }^{15}$ The CBC usually contains the terminal branches of the biliary tree, so the primary suture of the $\mathrm{CBC}$ is generally sufficient. Also, we usually use the drains for cyst cavity considering the postoperative biliary leakage. Furthermore, preoperative

Table 3 The distribution of the cysts in the liver according to distance from the hilus and the ratio of $C B C$

\begin{tabular}{lll}
\hline & CBC (\%) & Total (\%) \\
\hline Hilar $^{\mathrm{b}}$ & $3 \mathrm{I} / 84(36.9)$ & $84(55.3)$ \\
Peripheral $^{\mathrm{d}}$ & $24 / 68(35.3)$ & $68(44.7)$ \\
Total $^{\mathrm{b}}$ & $55 / 152(36.2)$ & $152(100)$ \\
\hline
\end{tabular}

Notes: ${ }^{\mathrm{T} T h e}$ rate of $C B C$ in each stage. ${ }^{\mathrm{b}}$ The rate of cyst localization. 'Segments I, 3, 4b, 5, and 6. 'Segments 2, 4a, 7, and 8.

Abbreviation: $\mathrm{CBC}$, cystobiliary communication.
Table 4 The distribution of the cysts according to the Gharbi classification and the ratio of $\mathrm{CBC}$

\begin{tabular}{llll}
\hline Stage & CBC (\%) & Total (\%) & P-value $^{\mathrm{c}}$ \\
\hline $\mathrm{I}$ & $17 / 62(27.4)$ & $62(40.8)$ & 0.108 \\
2 & $5 / 17(29.4)$ & $17(11.2)$ & \\
3 & $23 / 55(41.8)$ & $55(36.2)$ & \\
4 & $10 / 18(55.6)$ & $18(11.8)$ & \\
5 & 0 & $0(0)$ & \\
Total & $55 / 152$ & $152(100)$ & \\
\hline
\end{tabular}

Notes: ${ }^{2} T$ he rate of $C B C$ in each stage. ${ }^{b}$ The rate of cyst stage for all cysts. 'Fisher's exact test.

Abbreviation: $C B C$, cystobiliary communication.

endoscopic retrograde cholangiopancreatography can be performed, if necessary.

Abdominal ultrasonography, $\mathrm{CT}$, and magnetic resonance cholangiopancreatography are the main diagnostic modalities in the determination of hydatid cysts. ${ }^{10,16}$ Radiological findings suggesting the presence of $\mathrm{CBC}$ include deterioration of the integrity of the cyst wall and the presence of a connection between the biliary tract and the hydatid cyst with cystic material in the biliary tract. ${ }^{24}$ On ultrasound, ruptured materials in the biliary tract appear as various anechoic or hypoechoic shapes without acoustic shadowing. However, fragmented membranes can appear as highly echogenic linear structures. ${ }^{16,24}$ On CT, the materials in the intrahepatic bile ducts can appear as highdensity linear structures. The loss of integrity of the cyst wall suggests $\mathrm{CBC}$. These findings, together with materials in the biliary tree or expansion of the portal vein and biliary tree, suggest the existence of a major connection. ${ }^{25}$

Ultrasonography can detect a connection in $30 \%-74 \%$ of patients having major $\mathrm{CBC}$ preoperatively. ${ }^{24-27} \mathrm{CT}$ detects $75 \%$ of major $\mathrm{CBC}$ cases and allows for the evaluation of other organs. ${ }^{11,24}$ In our study, the abdominal CT revealed major $\mathrm{CBC}$ in $45 \%$ of the patients and operation notes detected minor $\mathrm{CBC}$ in $55 \%$ of the patients. In this study, we sought to find whether radiographic location of the cysts affects the diagnosis of minor and major CBCs.

Hepatic cyst hydatid disease most commonly involves the right lobe $(66 \%-78 \%){ }^{8,28-32}$ Right liver lobe involvement was reported to be $69.4 \%$ and $66 \%$ in the studies of Aday et $\mathrm{al}^{32}$ and Kayaalp et $\mathrm{al},{ }^{8}$ respectively. In our study, we found right lobe involvement in $61.8 \%$ of cases. The cysts show a preference for the right lobe as a result of the spread of echinococcosis into the bigger anatomical liver, which drains more blood through the portal vein. Kayaalp et a $1^{8}$ reported that CBC developed in $46 \%$ of the left lobe cysts, $31 \%$ of the right lobe cysts, and $100 \%$ of the caudate lobe cysts. However, in our study, CBC development was most 
Table 5 The relation of the demographic findings of the cysts and the patients and preoperative laboratory results in terms of CBC

\begin{tabular}{|c|c|c|c|}
\hline \multirow[t]{2}{*}{ Parameters } & \multicolumn{2}{|l|}{ Groups } & \multirow[t]{2}{*}{$P$-value } \\
\hline & CBC (-) & CBC (+) & \\
\hline Age (years) & $38.95 \pm 14.97$ & $39.77 \pm 18.48$ & NS \\
\hline \multicolumn{4}{|l|}{ Sex, n (\%) } \\
\hline Men & $17(53.1)$ & I5 (44.9) & NS \\
\hline Women & $46(58.2)$ & $33(41.8)$ & \\
\hline Number of lesions & $1.53 \pm 0.90$ & $1.08 \pm 0.28$ & 0.002 \\
\hline Diameter of the cysts $(\mathrm{mm})$ & $61.57 \pm 24.67$ & $93.33 \pm 39.28$ & $\leq 0.001$ \\
\hline WBCs $\left(\mathrm{mm}^{3}\right)$ & $8.88 \pm 3.44$ & $9.26 \pm 3.50$ & NS \\
\hline $\mathrm{Hb}(\mathrm{g} / \mathrm{dL})$ & $12.98 \pm 4.12$ & $13.17 \pm 4.17$ & NS \\
\hline Hct (\%) & $37.57 \pm 9.36$ & $40.21 \pm 9.19$ & NS \\
\hline TB (mg/dL) & $0.63 \pm 0.73$ & $\mathrm{I} .5 \mathrm{I} \pm 2.67$ & 0.031 \\
\hline $\mathrm{DB}(\mathrm{mg} / \mathrm{dL})$ & $0.34 \pm 0.56$ & $0.96 \pm 2.09$ & 0.044 \\
\hline AST (U/L) & $29.03 \pm 33.90$ & $38.08 \pm 36.05$ & NS \\
\hline $\mathrm{ALT}(\mathrm{U} / \mathrm{L})$ & $37.87 \pm 60.3$ & $47.10 \pm 57.52$ & NS \\
\hline ALP (U/L) & $79.32 \pm 75.99$ & $235.04 \pm 134.75$ & $\leq 0.001$ \\
\hline GGT (U/L) & $42.40 \pm 42.21$ & $215.06 \pm 193.39$ & $\leq 0.001$ \\
\hline
\end{tabular}

Notes: Results are in response to Student's $t$ test. $P$-values were considered significant at the $\alpha 0.05$ level. All values are mean \pm SD unless otherwise stated. Abbreviations: CBC, cystobiliary communication; NS, not significant; WBC, white blood cell; Hb, hemoglobin; Hct, hematocrit; TB, total bilirubin; DB, direct bilirubin; AST, aspartate aminotransferase; ALT, alanine transaminase; ALP, alkaline phosphatase; GGT, gamma-glutamyl transferase.

common in the right lobe cysts $(40.4 \%)$. Although caudate hydatid cyst is a rare entity $(1.3 \%), \mathrm{CBC}$ development ratio was as high as $50 \%$.

The cysts tended to localize in segments 4 and 8, and CBC development was more common in cysts located in segments 1, 4, 7, and 8. Similarly, segments 1, 4, 7, and 8 were found to be related to $\mathrm{CBC}$ presence in the study of Kilic et al. ${ }^{9}$ In another study, although the cysts were more common in segments 7 and 8, CBC presence was more frequent in segments $1,2,3,4 \mathrm{~b}$, and $5 .^{8}$

Perdomo et $\mathrm{al}^{33}$ reported that $\mathrm{CBC}$ is more common in cyts located close to the hilus, and that these hilar cysts are responsible for many serious complications. Likewise, Kayaalp et $\mathrm{al}^{8}$ found that cysts located close to the hilus tended to rupture into the biliary system. In our study, although $\mathrm{CBC}$ was more common in cysts located close to the hilus than cysts far from the hilus $(36.9 \%$ vs $35.3 \%$, respectively), this difference was not statistically significant.
The slightly more common presence of CBC in cysts located close the hilus may be related to the number and density of perihilar biliary tracts in these areas.

In relating $\mathrm{CBC}$ to the Gharbi morphological classification of cysts, El Malki et $\mathrm{al}^{7}$ detected CBC frequencies of $27 \%$ and $31.7 \%$ in stage 3 and 4 cysts (multilocular and degenerated), respectively. As a result, they stated that stage 3 and 4 morphological structures were the main risk factors for CBC development. Our study results are in parallel with these data.

Kilic et $\mathrm{al}^{9}$ proposed a cyst diameter of $\geq 7.5 \mathrm{~cm}$ as a risk factor for the intraoperative $\mathrm{CBC}$ presence and postoperative biliary fistula development. Demircan et $\mathrm{al}^{22}$ reported cyst diameters $>8.5$ and $10 \mathrm{~cm}$ as risk factors for intraoperative $\mathrm{CBC}$ presence and postoperative biliary fistula development, respectively. However, Kayaalp et $\mathrm{al}^{8}$ could not demonstrate any relation between cyst size and $\mathrm{CBC}$, and they emphasized that other factors may be more important than the cyst size. In the study of El Malki et al, ${ }^{7}$ there was no independent

Table 6 The linear regression analyses of predictive factors in determining CBC preoperatively

\begin{tabular}{|c|c|c|c|c|c|}
\hline \multirow[t]{2}{*}{ Model } & \multicolumn{2}{|c|}{$\begin{array}{l}\text { Unstandardized } \\
\text { coefficients }\end{array}$} & \multirow{2}{*}{$\begin{array}{l}\text { Standardized } \\
\text { coefficients } \\
\beta\end{array}$} & \multirow[t]{2}{*}{$t$} & \multirow[t]{2}{*}{ Sig } \\
\hline & $\beta$ & Std error & & & \\
\hline Constant & -0.081 & 0.129 & & -0.627 & 0.532 \\
\hline Number of lesions & -0.120 & 0.049 & -0.177 & -2.432 & 0.017 \\
\hline The diameter of the cysts $(\mathrm{mm})$ & 0.005 & 0.001 & 0.362 & 4.853 & 0.000 \\
\hline ALP & 0.001 & 0.000 & 0.283 & 2.440 & 0.016 \\
\hline GGT & 0.001 & 0.000 & 0.222 & 1.946 & 0.049 \\
\hline
\end{tabular}

Abbreviations: CBC, cystobiliary communication; Std error, standard error; ALP, alkaline phosphatase; GGT, gamma-glutamyl transferase. 
relationship between cyst diameter and $\mathrm{CBC}$ development. Additionally, they reported that $\mathrm{CBC}$ frequency was highest in patients with two cysts. In our study, patients with $\mathrm{CBC}$ had high cyst diameter and low cyst number $(P<0.05)$. As the cyst size is larger in patients with a single cyst, since more pericystic walls exist in patients with a single large size of cyst, the relationship between these cysts with the biliary tract is much more; therefore, fistulization is seen more frequently. ${ }^{34}$

Atli et $\mathrm{al}^{35}$ showed that ALP $>144 \mathrm{U} / \mathrm{L}$ and TB $>0.8 \mathrm{mg} / \mathrm{dL}$ successfully predicted CBC presence. In a study conducted by Demircan et al, ${ }^{22}$ ALP $>250 \mathrm{U} / \mathrm{L}, \mathrm{TB}>17.1 \mu \mathrm{mol} / \mathrm{L}$, $\mathrm{DB}>6.8 \mu \mathrm{mol} / \mathrm{L}$, and GGT $>34.5 \mathrm{U} / \mathrm{L}$ were shown to be independent predictors for CBC development. The most important parameter was the high level of ALP. Likewise, ALP, GGT, TB, and DB values were significantly higher in patients with $\mathrm{CBC}$ than in those without $\mathrm{CBC}(P<0.05)$. These elevated levels result from drainage of the cyst content into the biliary system. ${ }^{22}$

The first main limitation of this study was its retrospective design. Therefore, additional parameters, such as hydatid serology, repeated procedures, and albendazole treatment, could not be studied. The patients undergoing radical procedures were excluded from this study because CBC presence was not researched in the specimens. The second main limitation was the relatively small size of the study group.

\section{Conclusion}

Segmental and lobar localization, diameter, number, and morphological stage of the cysts can be determined by abdominal CT. These factors, along with preoperative ALP and GGT values, can be predictive of the presence of $\mathrm{CBC}$.

\section{Disclosure}

The authors report no conflicts of interest in this work.

\section{References}

1. Menezes da Silva A. Hydatid cyst of the liver-criteria for the selection of appropriate treatment. Acta Trop. 2003;85(2):237-242.

2. Aziz F, Pandya T, Patel HV, et al. Nephrotic presentation in hydatid cyst disease with predominant tubulointerstital disease. Int J Nephrol Renovasc Dis. 2009;2:23-26.

3. Avcu S, Ünal Ö, Arslan H. Intrabiliary rupture of liver hydatid cyst: a case report and review of the literature. Cases J. 2009;2:6455.

4. Hankıns JR. Management of complicated hepatic hydatid cysts. Ann Surg. 1963;158:1020-1034.

5. Manouras A, Genetzakis M, Antonakis PT, et al. Endoscopic management of a relapsing hepatic hydatid cyst with intrabiliary rupture: a case report and review of the literature. Can J Gastroenterol. 2007;21(4): 249-253.

6. Erzurumlu K, Dervisoglu A, Polat C, Senyurek G, Yetim I, Hokelek M. Intrabiliary rupture: an algorithm in the treatment of controversial complication of hepatic hydatidosis. World J Gastroenterol. 2005; 11(16):2472-2476.
7. El Malki HO, El Mejdoubi Y, Souadka A, et al. Predictive model of biliocystic communication in liver hydatid cysts using classification and regression tree analysis. BMC Surg. 2010;10:16.

8. Kayaalp C, Bostanci B, Yol S, Akoglu M. Distribution of hydatid cysts into the liver with reference to cystobiliary communications and cavityrelated complications. Am J Surg. 2003;185(2):175-179.

9. Kilic M, Yoldas O, Koc M, et al. Can biliary-cyst communication be predicted before surgery for hepatic hydatid disease: does size matter? Am J Surg. 2008;196(5):732-735.

10. Erden A, Ormeci N, Fitoz S, Erden I, Tanju S, Genç Y. Intrabiliary rupture of hepatic hydatid cysts: diagnostic accuracy of MR cholangiopancreatography. AJR Am J Roentgenol. 2007;189(2): 84-89.

11. Prousalidis J, Kosmidis C, Anthimidis G, Fachantidis E, Harlaftis N, Aletras H. Forty-four years' experience (1963-2006) in the management of primarily infected hydatid cyst of the liver. HPB (Oxford). 2008; 10(1):18-24.

12. Couinaud C. Surgical Anatomy of the Liver Revisited. Paris: Couinaud; 1989.

13. Bismuth H. Surgical anatomy and anatomical surgery of the liver. World J Surg. 1982;6(1):3-9.

14. Gharbi HA, Hassine W, Brauner MW, Dupuch K. Ultrasound examination of the hydatid liver. Radiology. 1981;139(2):459-463.

15. Prousalidis J, Kosmidis C, Kapoutzis K, Fachantidis E, Harlaftis N, Aletras H. Intrabiliary rupture of hydatid cysts of the liver. Am J Surg. 2009;197(2):193-198.

16. Valle-Sanz Yd Y, Lorente-Ramos RM. Sonographic and computed tomographic demonstration of hydatid cysts communicating with the biliary tree. J Clin Ultrasound. 2004;32(3):144-148.

17. Safioleas MC, Misiakos EP, Kouvaraki M, Stamatakos MK, Manti CP, Felekouras ES. Hydatid disease of the liver: a continuing surgical problem. Arch Surg. 2006;141(11):1101-1108.

18. Malik AA, Bari SU, Amin R, Jan M. Surgical management of complicated hydatid cysts of the liver. World J Gastrointest Surg. 2010;2(3): $78-84$.

19. Bedirli A, Sakrak O, Sozuer EM, Kerek M, Ince O. Surgical management of spontaneous intrabiliary rupture of hydatid liver cysts. Surg Today. 2002;32(7):594-597.

20. Manterola C, Vial M, Sanhueza A, Contreras J. Intrabiliary rupture of hepatic echinococcosis, a risk factor for developing postoperative morbidity: a cohort study. World J Surg. 2010;34(3):581-586.

21. Galati G, Sterpetti AV, Caputo M, et al. Endoscopic retrograde cholangiography for intrabiliary rupture of hydatid cyst. Am J Surg. 2006; 191(2):206-210.

22. Demircan O, Baymus M, Seydaoglu G, Akinoglu A, Sakman G. Occult cystobiliary communication presenting as postoperative biliary leakage after hydatid liver surgery: are there significant preoperative clinical predictors? Can J Surg. 2006;49(3):177-184.

23. Saylam B, Coşkun F, Demiriz B, Vural V, Comçali B, Tez M. A new and simple score for predicting cystobiliary fistula in patients with hepatic hydatid cysts. Surgery. 2013;153(5):699-704.

24. Pedrosa I, Saíz A, Arrazola J, Ferreirós J, Pedrosa CS. Hydatid disease: radiologic and pathologic features and complications. Radiographics. 2000;20(3):795-817.

25. Mendez Montero JV, Arrazola Garcia J, Lopez Lafuente J, Antela Lopez J, Mendez Fernandez R, Saiz Ayala A. Fat-fluid level in hepatic hydatid cyst: a new sign of rupture into the biliary tree? AJR Am J Roentgenol. 1996;167(1):91-94.

26. Yildirgan MI, Başoğlu M, Atamanalp SS, et al. Intrabiliary rupture in liver hydatid cysts: results of 20 years' experience. Acta Chir Belg. 2003; 103(6):621-625.

27. Kumar R, Reddy SN, Thulkar S. Intrabiliary rupture of hydatid cyst: diagnosis with MRI and hepatobiliary isotope study. Br J Radiol. 2002; 75(891):271-274.

28. Yilmaz E, Gökok N. Hydatid disease of the liver: current surgical management. Br J Clin Pract. 1990;44(12):612-615. 
29. Langer JC, Rose DB, Keystone JS, Taylor BR, Langer B. Diagnosis and management of hydatid disease of the liver. A 15-year North American experience. Ann Surg. 1984;199(4):412-417.

30. Sayek I, Yalin R, Sanaç Y. Surgical treatment of hydatid disease of the liver. Arch Surg. 1980;115(7):847-850.

31. Demirci S, Eraslan S, Anadol E, Bozatli L. Comparison of the results of different surgical techniques in the management of hydatid cysts of the liver. World J Surg. 1989;13(1):88-90.

32. Aday U, Kapan M, Önder A, et al. Liver hydatid cyst associated with biliary tract: is it an important complication indicator? J Curr Surg. 2011; $1(1): 25-32$.
33. Perdomo R, Alvarez C, Monti J, et al. Principles of the surgical approach in human liver cystic echinococcosis. Acta Trop. 1997;64(1-2): $109-122$.

34. Gahukamble DB, Khamage AS, Gahukamble LD. Outcome of minimal surgery for hydatid cysts of the liver in children with reference to postoperative biliary leakage. Ann Trop Paediatr. 2000;20(2):147-151.

35. Atli M, Kama NA, Yuksek YN, et al. Intrabiliary rupture of a hepatic hydatid cyst: associated clinical factors and proper management. Arch Surg. 2001;136(11):1249-1255.

\section{Publish your work in this journal}

Therapeutics and Clinical Risk Management is an international, peerreviewed journal of clinical therapeutics and risk management, focusing on concise rapid reporting of clinical studies in all therapeutic areas outcomes, safety, and programs for the effective, safe, and sustained use of medicines. This journal is indexed on PubMed Central, CAS,
EMBase, Scopus and the Elsevier Bibliographic databases. The manuscript management system is completely online and includes a very quick and fair peer-review system, which is all easy to use. Visit http://www.dovepress.com/testimonials.php to read real quotes from published authors.

Submit your manuscript here: http://www.dovepress.com/therapeutics-and-clinical-risk-management-journal 